\title{
THE REMOTE SENSING IMAGE GEOMETRICAL MODEL OF BP NEURAL NETWORK
}

\author{
C. Y. Yue ${ }^{1,2 *}$, T. $\operatorname{Sun}^{3}$, J. F. Xie ${ }^{4}$ \\ ${ }^{1}$ Beijing Institute of Space Mechanics \& Electricity, Beijing, China - ycy1893@163.com \\ ${ }^{2}$ Beijing Key Laboratory of Advanced Optical Remote Sensing Technology, Beijing, China \\ ${ }^{3}$ Key Laboratory of Technology in Geo-spatial Information Processing and Application System, Aerospace Information Research \\ Institute, Chinese Academy of Sciences, Beijing,China - ts-1@live.cn \\ ${ }^{4}$ Land Satellite Remote Sensing Application Center, Ministry of Natural Resources of P. R. China, Beijing, China - \\ junfeng_xie@163.com
}

KEY WORDS: Imagery geometry model (IGM), Back propagation (BP) neural network, Rigorous sensor models (RSM), Generalized sensor models, Rational polynomial coefficients (RPCs)

\begin{abstract}
:
Imagery geometry models (IGMs) of the high-resolution satellite images (HRSIs) are always of great interest in the photogrammetry and remote sensing community for the raising new kinds of sensors and imaging systems. Especially the generalized sensor models (GSMs) have been widely used for positioning of satellite images, and the accuracy are already validated. Since Back propagation (BP) neural network is a better choice for the two key reasons of the replacement of physical sensor models by generalized sensor models, numerous mathematical estimations for every specialized sensor, and secret equations of the IGMs. Experiments are carried out to test the approximation accuracy of the new generalized sensor model. And the experimental results show that, the BP neural network is of extremely high accuracy for satellite imagery photogrammetric restitution.
\end{abstract}

\section{INTRODUCTION}

Geospatial information of high-resolution satellite images (HRSIs) are extracted via the functional relationship between the image space and object space, which is usually called imagery geometry model (IGM) (Tao and $\mathrm{Hu}, 2001$; Yue et al, 2013; Yavari et al, 2013). In general, the IGMs can be mainly categorized into two types: rigorous sensor models (RSM), which are physical sensor models of satellite ephemeris data (Radhadevi et al., 1998; Jeong and Kim, 2015), and generalized sensor models, such as rational polynomial coefficients (RPCs) model provided by the imagery vendor(Fraser et al., 2002; Grodecki and Dial, 2003; Zhang, G. and Yuan, X., 2006). RSMs were firstly used for the geopositioning of the satellite imagery, as it is the truly 'physical' procedure of imaging (Gugan and Dowman, 1988; Kim and Dowman, 2006). However, duo to the large number of types of sensors, there are a great need of processing different physical sensor models for each new sensor. In addition, most of the satellite sensor models in the world are not open to the public. Therefore, rational function model (RFM) parameters (RPCs) instead of RSMs are provided to the end users as the standard auxiliary data attaching to the imagery by the commercial vendors. Nowadays, the generalized sensor models have been widely used for positioning of satellite images, and the accuracy are validated(Fraser and Yamakawa, 2004; Tao et al., 2004; Zhao R., et al, 2017).

For the two key reasons of the replacement of physical sensor models by generalized sensor models, numerous mathematical estimations for every specialized sensor, and secret equations of the IGMs, the Back propagation (BP) neural network is carried out as a new generalized sensor model for its superior performance of nonlinear adaptive information in this paper(Xiao Z., et al, 2009).

Back propagation (BP) neural network is one of the most widely used neural network models in the artificial neural networks, and is already applied to solve the nonlinear positioning determination with high predictive accuracy in indoor positioning, GPS height conversion, et al(Hu C., 2010; Zhang H., 2012; Wang C., et al, 2016). However, there is no related studies about BP neural network in HRSIs geopositioing yet. In this paper, we are going to validate the BP neural network IGM for the replacement of physical sensor models. After the initial brief summary of the mathematical background of IGM and BP neural network, the BP neural network IGM is proposed. Then, the experiments of BP neural network fitting capability of the satellite physical sensor models, and the accuracy comparison experiment of BP neural network IGM and RFM are presented and analyzed. Finally, the experimental results demonstrate that, the BP neural network achieve a high fitting accuracy instead of the classical RFM algorithm, and can be applied to HRSIs geopositioning.

\section{METHODOLOGY}

\subsection{Imagery geometry model(IGM)}

\subsubsection{Rigorous sensor models (RSM)}

The strict imagery geometry model is the physical relationship between object coordinates and the image coordinates of the same point.

\footnotetext{
* Chunyu Yue, Email: ycy1893@163.com .
} 


$$
\left[\begin{array}{l}
\mathrm{X} \\
\mathrm{Y} \\
\mathrm{Z}
\end{array}\right]=\left[\begin{array}{l}
\mathrm{X}_{0} \\
\mathrm{Y}_{0} \\
\mathrm{Z}_{0}
\end{array}\right]+\lambda \mathrm{R}\left[\begin{array}{l}
\mathrm{x} \\
y \\
-\mathrm{f}
\end{array}\right]
$$

where $\lambda=$ scale factor

$\mathrm{f}=$ focal length

$\mathrm{R}=$ rotation matrix

$\mathrm{x}, \mathrm{y}=$ image coordinates

$\mathrm{X}_{0}, \mathrm{Y}_{0}, \mathrm{Z}_{0}=$ coordinates of projection center

$\mathrm{X}, \mathrm{Y}, \mathrm{Z}=$ object coordinates

In equation (1), satellite orbit data is to obtain the coordinates of projection center, satellite attitude data is to form the transformation between image coordinate system and space coordinate system, and the flight height of the satellite and focal length are used to calculate the scale factor, et al.

\subsubsection{Rational function model (RFM)}

Up to now, RFM is the most wildly used generalized sensor model by defining the positional relationship between object and image spaces, and is famous known as Rational Polynomial Coefficients (RPC) file attached to the imagery product.

The RFM is a ratio of two polynomial functions, and is expressed as:

$$
\begin{aligned}
& \mathrm{s}=\frac{\operatorname{Num}_{\mathrm{S}}(\mathrm{P}, \mathrm{L}, \mathrm{H})}{\operatorname{Den}_{\mathrm{S}}(\mathrm{P}, \mathrm{L}, \mathrm{H})} ; \quad 1=\frac{\operatorname{Num}_{\mathrm{L}}(\mathrm{P}, \mathrm{L}, \mathrm{H})}{\operatorname{Den}_{\mathrm{L}}(\mathrm{P}, \mathrm{L}, \mathrm{H})} \\
& \text { Num }_{\mathrm{L}}(\mathrm{P}, \mathrm{L}, \mathrm{H})=\mathrm{a}_{1}+\mathrm{a}_{2} \mathrm{~L}+\mathrm{a}_{3} \mathrm{P}+\mathrm{a}_{4} \mathrm{H}+\mathrm{a}_{5} \mathrm{LP}+\mathrm{a}_{6} \mathrm{LH} \\
& +\mathrm{a}_{7} \mathrm{PH}+\mathrm{a}_{8} \mathrm{~L}^{2}+\mathrm{a}_{9} \mathrm{P}^{2}+\mathrm{a}_{10} \mathrm{H}^{2}+\mathrm{a}_{11} \mathrm{PLH} \\
& +\mathrm{a}_{12} \mathrm{~L}^{3}+\mathrm{a}_{13} \mathrm{LP}^{2}+\mathrm{a}_{14} \mathrm{LH}^{2}+\mathrm{a}_{15} \mathrm{~L}^{2} \mathrm{P}+\mathrm{a}_{16} \mathrm{P}^{3} \\
& +\mathrm{a}_{17} \mathrm{PH}^{2}+\mathrm{a}_{18} \mathrm{~L}^{2} \mathrm{H}+\mathrm{a}_{19} \mathrm{P}^{2} \mathrm{H}+\mathrm{a}_{20} \mathrm{H}^{3} \\
& \operatorname{Den}_{\mathrm{L}}(\mathrm{P}, \mathrm{L}, \mathrm{H})=\mathrm{b}_{1}+\mathrm{b}_{2} \mathrm{~L}+\mathrm{b}_{3} \mathrm{P}+\mathrm{b}_{4} \mathrm{H}+\mathrm{b}_{5} \mathrm{LP}+\mathrm{b}_{6} \mathrm{LH} \\
& +\mathrm{b}_{7} \mathrm{PH}+\mathrm{b}_{8} \mathrm{~L}^{2}+\mathrm{b}_{9} \mathrm{P}^{2}+\mathrm{b}_{10} \mathrm{H}^{2}+\mathrm{b}_{11} \mathrm{PLH} \\
& +b_{12} L^{3}+b_{13} L^{2}+b_{14} L^{2}+b_{15} L^{2} P+b_{16} P^{3} \\
& +\mathrm{b}_{17} \mathrm{PH}^{2}+\mathrm{b}_{18} \mathrm{~L}^{2} \mathrm{H}+\mathrm{b}_{19} \mathrm{P}^{2} \mathrm{H}+\mathrm{b}_{20} \mathrm{H}^{3} \\
& N u m_{\mathrm{s}}(\mathrm{P}, \mathrm{L}, \mathrm{H})=\mathrm{c}_{1}+\mathrm{c}_{2} \mathrm{~L}+\mathrm{c}_{3} \mathrm{P}+\mathrm{c}_{4} \mathrm{H}+\mathrm{c}_{5} \mathrm{LP}+\mathrm{c}_{6} \mathrm{LH} \\
& +\mathrm{c}_{7} \mathrm{PH}+\mathrm{c}_{8} \mathrm{~L}^{2}+\mathrm{c}_{9} \mathrm{P}^{2}+\mathrm{c}_{10} \mathrm{H}^{2}+\mathrm{c}_{11} \mathrm{PLH} \\
& +\mathrm{c}_{12} \mathrm{~L}^{3}+\mathrm{c}_{13} \mathrm{LP}^{2}+\mathrm{c}_{14} \mathrm{LH}^{2}+\mathrm{c}_{15} \mathrm{~L}^{2} \mathrm{P}+\mathrm{c}_{16} \mathrm{P}^{3} \\
& +\mathrm{c}_{17} \mathrm{PH}^{2}+\mathrm{c}_{18}{ }^{2} \mathrm{H}+\mathrm{c}_{19} \mathrm{P}^{2} \mathrm{H}+\mathrm{c}_{20} \mathrm{H}^{3} \\
& \operatorname{Den}_{\mathrm{S}}(\mathrm{P}, \mathrm{L}, \mathrm{H})=\mathrm{d}_{1}+\mathrm{d}_{2} \mathrm{~L}+\mathrm{d}_{3} \mathrm{P}+\mathrm{d}_{4} \mathrm{H}+\mathrm{d}_{5} \mathrm{LP}+\mathrm{d}_{6} \mathrm{LH} \\
& +\mathrm{d}_{7} \mathrm{PH}+\mathrm{d}_{8} \mathrm{~L}^{2}+\mathrm{d}_{9} \mathrm{P}^{2}+\mathrm{d}_{10} \mathrm{H}^{2}+\mathrm{d}_{11} \mathrm{PLH} \\
& +\mathrm{d}_{12} \mathrm{~L}^{3}+\mathrm{d}_{13} \mathrm{LP}^{2}+\mathrm{d}_{14} \mathrm{LH}^{2}+\mathrm{d}_{15} \mathrm{~L}^{2} \mathrm{P}+\mathrm{d}_{16} \mathrm{P}^{3} \\
& +\mathrm{d}_{17} \mathrm{PH}^{2}+\mathrm{d}_{18} \mathrm{~L}^{2} \mathrm{H}+\mathrm{d}_{19} \mathrm{P}^{2} \mathrm{H}+\mathrm{d}_{20} \mathrm{H}^{3}
\end{aligned}
$$

where $\mathrm{s}, \mathrm{l}=$ normalized column and row

$\mathrm{P}, \mathrm{L}, \mathrm{H}=$ normalized longitude, latitude, height

$a_{1} \ldots a_{20}, b_{1} \ldots b_{20}, c_{1} \ldots c_{20}, d_{1} \ldots d_{20}=$ coefficients of the polynomial function

RFM needs plenty of ground control points (GCPs) to calculate the rational polynomial coefficients. Each GCP with its image point can form a pair of equations like equation (2), with their coordinates of both image and object space. Usually, the RPCs are solved via a least square fitting.

\subsection{BP neural network}

Back Propagation (BP) Neural Network is one of the most popular Neural Networks (NN), which are used to build a machine that will mimic brain activities and be able to learn like human beings. As is shown in Fig.1, there are three layers, input, output and hidden layer, composed in the basic NN, and so is BP Neural Network. Every layer of the three can have a certain number of nodes. From input layer to output layer, the nodes from input layer are connected to the nodes from hidden layer, and nodes from hidden layer are connected to the nodes from output layer.

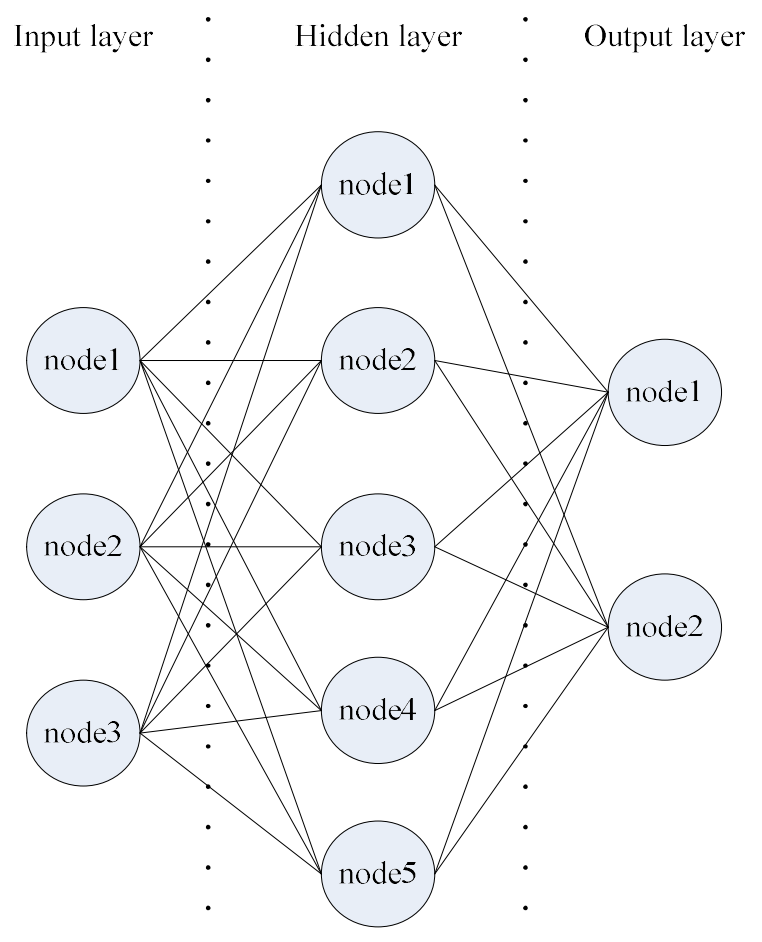

Figure 1. A BP neural network example

Each connection means the weight between input node and output node. In the training process, the output of NN is evaluated against desired output. The weights are modified again and again to repeat the training process until the error is small enough. For BP algorithm, the training process is broken down to three main steps:

i Feed-forward computation

ii Back propagation to the output layer, then the hidden layer

iii Weight updates for all the connections

\subsection{BP neural network imagery geometrical model}

The proposed method based on BP neural network is presented with training set of control points of both image coordinates and ground coordinates, which is very alike with the RFM, and is also can be categorized into two scenarios: terrain-dependent or not. When the physical sensor model is available, the training process is a terrain-independent solution. If not, the training result is highly dependent on the quality of input control points selected from the terrain surface.

The inputs of each point of the training set are its image coordinates $\mathrm{x}$ and $\mathrm{y}$, and height $\mathrm{Z}$, outputs are its ground coordinates $\mathrm{X}$ and $\mathrm{Y}$. The BP neural network imagery geometrical model can be written as:

$$
(\mathrm{X}, \mathrm{Y}) \quad \mathrm{f}(\mathrm{x}, \mathrm{y}, \mathrm{Z})
$$

where $\quad \mathrm{f}=\mathrm{BP}$ neural network imagery geometrical model In function (4), as is shown in Fig. 1, there are three nodes in the input layer, and two nodes in the output layer.

The flow chat of the method is shown as below. 


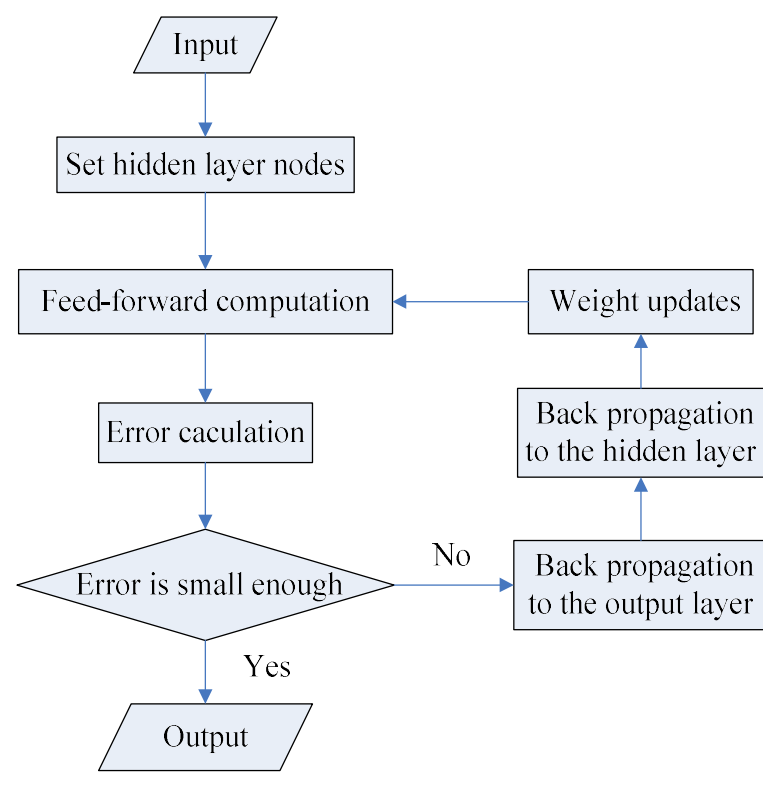

Figure 2. The BP neural network imagery geometrical model calculation method

\subsubsection{Feed-forward computation}

First set the number of nodes, $\mathrm{N}$, in the hidden layer and initial weights of each connections, in the BP neural network. Then, compute the values of each node in the hidden layer using the input values.Finally, repeat the computation with the values of the hidden layer nodes to get the output values.

$$
\begin{gathered}
\mathrm{NV}_{\mathrm{i}}=\mathrm{f}\left(\mathrm{x} \times \mathrm{w}_{\mathrm{xi}}+\mathrm{y} \times \mathrm{w}_{\mathrm{yi}}+\mathrm{Z} \times \mathrm{w}_{\mathrm{Zi}}\right) \\
\mathrm{X}=\mathrm{f}\left(\sum \mathrm{NV}_{\mathrm{i}} \times \mathrm{w}_{\mathrm{iX}}\right) \\
\mathrm{Y}=\mathrm{f}\left(\sum \mathrm{NV}_{\mathrm{i}} \times \mathrm{w}_{\mathrm{i}}\right)
\end{gathered}
$$

where $\quad \mathrm{NV}_{\mathrm{i}}=$ node value in the hidden layer

$\mathrm{i}=1,2 \ldots \mathrm{N}$

$\mathrm{x}, \mathrm{y}=$ image coordinates

$\mathrm{w}_{\mathrm{xi}}, \mathrm{w}_{\mathrm{yi}}, \mathrm{w}_{\mathrm{Zi}}=$ weights of the connections between input layer and hidden layer

$\mathrm{w}_{\mathrm{iX}}, \mathrm{w}_{\mathrm{iY}}=$ weights of the connections between hidden layer and output layer

$\mathrm{X}, \mathrm{Y}, \mathrm{Z}=$ ground coordinates

\subsubsection{Back propagation and Weights updates}

The errors of each node in output layer between feed-forward computation values and real output values are calculated first for the backward propagation from output layer to hidden layer, and the weights adjustment.

$$
\begin{aligned}
& \mathrm{E}_{\mathrm{X}}=\mathrm{X} \times\left(\mathrm{X}_{\mathrm{c}}-\mathrm{X}\right)^{2} \\
& \Delta \mathrm{w}_{\mathrm{iX}}=\mathrm{E}_{\mathrm{X}} \times \mathrm{NV}_{\mathrm{i}} \times \beta \\
& \Delta \mathrm{w}_{\mathrm{iY}}=\mathrm{E}_{\mathrm{Y}} \times \mathrm{NV}_{\mathrm{i}} \times \beta \\
& \mathrm{w}_{\mathrm{iX} \_\mathrm{m}}=\mathrm{w}_{\mathrm{iX}}+\Delta \mathrm{w}_{\mathrm{iX}} \\
& \mathrm{w}_{\mathrm{iY}} \mathrm{m}=\mathrm{w}_{\mathrm{iY}}+\Delta \mathrm{w}_{\mathrm{iY}} \\
& \text { where } E_{X}, E_{Y}=\text { errors of output layer node } \\
& \Delta \mathrm{w}_{\mathrm{iX}}, \Delta \mathrm{w}_{\mathrm{iY}}=\text { correction of } \mathrm{w}_{\mathrm{iX}}, \mathrm{w}_{\mathrm{iY}} \\
& \beta=\text { learning rate } \\
& \mathrm{w}_{\mathrm{iX}}, \mathrm{w}_{\mathrm{iY}} \mathrm{m}=\text { modified weights of } \mathrm{w}_{\mathrm{iX}}, \mathrm{w}_{\mathrm{iY}}
\end{aligned}
$$

Then, the errors of each node in output layer are multiplied with weights and values of their connecting nodes in the hidden layer for the backward propagation from hidden layer output layer to input layer, and the weights adjustment.

$$
\begin{aligned}
& \mathrm{E}_{\mathrm{NVi}}=\mathrm{E}_{\mathrm{X}} \times \mathrm{w}_{\mathrm{iX} \_\mathrm{m}}+\mathrm{E}_{\mathrm{Y}} \times \mathrm{w}_{\mathrm{iY} \_} \mathrm{m} \\
& \Delta \mathrm{w}_{\mathrm{xi}}=\mathrm{E}_{\mathrm{NVi}} \times \mathrm{x} \times \beta \\
& \Delta \mathrm{w}_{\mathrm{yi}}=\mathrm{E}_{\mathrm{NVi}} \times \mathrm{y} \times \beta \\
& \Delta \mathrm{w}_{\mathrm{Zi}}=\mathrm{E}_{\mathrm{NVi}} \times \mathrm{Z} \times \beta
\end{aligned}
$$

$$
\mathrm{w}_{\mathrm{xi} \_\mathrm{m}}=\mathrm{w}_{\mathrm{xi}}+\Delta \mathrm{w}_{\mathrm{xi}}
$$

$$
\mathrm{W}_{\mathrm{yi} \_\mathrm{m}}=\mathrm{w}_{\mathrm{yi}}+\Delta \mathrm{w}_{\mathrm{yi}}
$$$$
\mathrm{w}_{\mathrm{Zi} \mathrm{m}}=\mathrm{w}_{\mathrm{Zi}}+\Delta \mathrm{w}_{\mathrm{Zi}}
$$

where $\quad \mathrm{E}_{\mathrm{NVi}}=$ errors of hidden layer node

$\Delta \mathrm{w}_{\mathrm{xi}}, \Delta \mathrm{w}_{\mathrm{yi}}, \Delta \mathrm{w}_{\mathrm{Zi}}=$ correction of $\mathrm{w}_{\mathrm{xi}}, \mathrm{w}_{\mathrm{yi}}, \mathrm{w}_{\mathrm{Zi}}$

$\mathrm{w}_{\mathrm{xi} \_\mathrm{m}}, \mathrm{w}_{\mathrm{yi} \_\mathrm{m}}, \mathrm{w}_{\mathrm{Zi} \_\mathrm{m}}=$ modified weights of $\mathrm{w}_{\mathrm{xi}}, \mathrm{w}_{\mathrm{yi}}, \mathrm{w}_{\mathrm{Zi}}$

After all the errors have been calculated, every weight is updated, and the new iteration begins. The process is repeated again and again, until the errors are small enough.

\section{EXPERIMENT AND RESULT}

\subsection{Datasets for study}

GF-2 satellite images of mountain, hill, and city ares are used in this study. The properties of the test images are shown in Table 1.

\begin{tabular}{|l|c|c|c|}
\hline Dataset & 1 & 2 & 3 \\
\hline Land cover & mountain & hill & city \\
Image size & $29200 \times 27620$ & $29200 \times 30395$ & $29200 \times 27620$ \\
Resolution & $0.81 \mathrm{~m}$ & $0.81 \mathrm{~m}$ & $0.81 \mathrm{~m}$ \\
Location & Songshan, & Baguacheng, & Paris, \\
& China & China & France \\
Image time & 2019.03.12 & 2017.08.29 & 2016.04.20 \\
\hline
\end{tabular}

GF-2 satellite was designed and developed by CAST (China Academy of Space Technology). It employs the CAST-CSL3000A bus and two PAN/MS cameras, with a GSD (Ground Sampling Distance) of $0.81 \mathrm{~m}$ in panchromatic and $3.24 \mathrm{~m}$ in multispectral bands on a swath of $45 \mathrm{~km}$.

For dataset 1, we have both physical sensor model and GCPs. And we can do both terrain-dependent and terrain-independent experiments. For dataset 2 and 3, we only have physical sensor model. So we can only do the terrain-independent experiments.

\subsection{Experimental result and analysis}

For the terrain-independent experiments, a 3D GCPs grid of $10 \times 10 \times 5$, and a $3 \mathrm{D}$ check points grid of $5 \times 5 \times 5$ are established to train and check the BP neural network. And the results are listed in Tables 2-4. The fitting accuracy with different node number of the hidden layer of the three datasets is shown in Figure 3.

For the terrain-dependent experiment, 100 GCP's among the image uniform distributed are selected as training dataset, and other 22 check points also uniform distributed in the image are used to check the accuracy. The terrain-dependent result is listed in Table 5. The fitting accuracy with different node number of the hidden layer of dataset 1 is shown in Figure 4.

The relative classical RFM are chosen and solved in the same way of Zhang, G. and Yuan, X., 2006, results are listed in Table 6 , including both terrain-dependent experiment and terrainindependent experiments. 


\begin{tabular}{|c|c|c|c|c|c|c|c|c|c|c|c|c|}
\hline \multirow{3}{*}{$\begin{array}{l}\text { Number } \\
\text { of node }\end{array}$} & \multicolumn{6}{|c|}{ Control point (pixel) } & \multicolumn{6}{|c|}{ Check point(pixel) } \\
\hline & \multicolumn{2}{|c|}{$\mathrm{X}$} & \multicolumn{2}{|c|}{$\mathrm{Y}$} & \multicolumn{2}{|c|}{ Planarity } & \multicolumn{2}{|c|}{$\mathrm{X}$} & \multicolumn{2}{|c|}{$\mathrm{Y}$} & \multicolumn{2}{|c|}{ Planarity } \\
\hline & Max & RMS & Max & RMS & Max & RMS & Max & RMS & Max & RMS & Max & RMS \\
\hline 2 & 3.35 & 1.39 & 3.94 & 1.03 & 5.10 & 0.87 & 3.17 & 1.43 & 2.96 & 0.99 & 4.86 & 0.87 \\
\hline 3 & 1.25 & 1.01 & 1.76 & 0.45 & 2.71 & 0.51 & 2.72 & 1.61 & 1.67 & 0.64 & 5.74 & 1.01 \\
\hline 4 & 0.13 & 0.04 & 0.08 & 0.04 & 0.13 & 0.02 & 0.56 & 0.20 & 0.30 & 0.11 & 0.56 & 0.11 \\
\hline 5 & 0.09 & 0.04 & 0.08 & 0.04 & 0.10 & 0.02 & 0.10 & 0.05 & 0.11 & 0.04 & 0.14 & 0.03 \\
\hline 6 & 0.09 & 0.04 & 0.08 & 0.04 & 0.11 & 0.02 & 0.08 & 0.04 & 0.08 & 0.03 & 0.09 & 0.02 \\
\hline 7 & 0.07 & 0.04 & 0.09 & 0.04 & 0.10 & 0.02 & 0.07 & 0.04 & 0.07 & 0.03 & 0.09 & 0.02 \\
\hline
\end{tabular}

Table 2. BP neural network imagery geometrical model accuracy of dataset 1

\begin{tabular}{|c|c|c|c|c|c|c|c|c|c|c|c|c|}
\hline \multirow{3}{*}{$\begin{array}{l}\text { Number } \\
\text { of node }\end{array}$} & \multicolumn{6}{|c|}{ Control point (pixel) } & \multicolumn{6}{|c|}{ Check point(pixel) } \\
\hline & \multicolumn{2}{|c|}{$\mathrm{X}$} & \multicolumn{2}{|c|}{ Y } & \multicolumn{2}{|c|}{ Planarity } & \multicolumn{2}{|c|}{$\mathrm{X}$} & \multicolumn{2}{|c|}{$\mathrm{Y}$} & \multicolumn{2}{|c|}{ Planarity } \\
\hline & Max & RMS & Max & RMS & $\operatorname{Max}$ & RMS & Max & RMS & Max & RMS & Max & RMS \\
\hline 2 & 5.16 & 1.95 & 7.07 & 1.91 & 7.93 & 1.33 & 5.09 & 1.95 & 6.90 & 2.08 & 7.81 & 1.44 \\
\hline 3 & 3.51 & 1.25 & 2.25 & 0.88 & 3.59 & 0.74 & 2.18 & 1.24 & 3.37 & 1.23 & 5.43 & 0.70 \\
\hline 4 & 0.22 & 0.07 & 0.20 & 0.07 & 0.28 & 0.05 & 0.21 & 0.08 & 0.14 & 0.06 & 0.24 & 0.05 \\
\hline 5 & 0.33 & 0.10 & 0.24 & 0.08 & 0.38 & 0.06 & 0.19 & 0.06 & 0.13 & 0.06 & 0.20 & 0.04 \\
\hline 6 & 0.29 & 0.09 & 0.30 & 0.08 & 0.33 & 0.05 & 0.09 & 0.04 & 0.09 & 0.04 & 0.11 & 0.02 \\
\hline 7 & 0.09 & 0.04 & 0.10 & 0.04 & 0.11 & 0.02 & 0.08 & 0.04 & 0.08 & 0.04 & 0.11 & 0.02 \\
\hline
\end{tabular}

Table 3. BP neural network imagery geometrical model accuracy of dataset 2

\begin{tabular}{|c|c|c|c|c|c|c|c|c|c|c|c|c|}
\hline \multirow{3}{*}{$\begin{array}{l}\text { Number } \\
\text { of node }\end{array}$} & \multicolumn{6}{|c|}{ Control point (pixel) } & \multicolumn{6}{|c|}{ Check point(pixel) } \\
\hline & \multicolumn{2}{|c|}{$\mathrm{X}$} & \multicolumn{2}{|c|}{$\mathrm{Y}$} & \multicolumn{2}{|c|}{ Planarity } & \multicolumn{2}{|c|}{$\mathrm{X}$} & \multicolumn{2}{|c|}{$\mathrm{Y}$} & \multicolumn{2}{|c|}{ Planarity } \\
\hline & Max & RMS & Max & RMS & Max & RMS & Max & RMS & Max & RMS & Max & RMS \\
\hline 2 & 7.93 & 2.28 & 12.97 & 3.34 & 14.35 & 2.21 & 7.27 & 2.29 & 8.52 & 3.24 & 9.95 & 2.05 \\
\hline 3 & 3.06 & 1.71 & 5.92 & 1.43 & 7.42 & 1.15 & 1.82 & 1.08 & 2.87 & 1.26 & 3.84 & 0.82 \\
\hline 4 & 0.13 & 0.05 & 0.15 & 0.05 & 0.17 & 0.03 & 0.17 & 0.08 & 0.22 & 0.06 & 0.22 & 0.05 \\
\hline 5 & 0.11 & 0.04 & 0.12 & 0.04 & 0.15 & 0.02 & 0.07 & 0.04 & 0.09 & 0.04 & 0.12 & 0.02 \\
\hline 6 & 0.09 & 0.04 & 0.12 & 0.04 & 0.13 & 0.02 & 0.07 & 0.04 & 0.11 & 0.04 & 0.11 & 0.02 \\
\hline 7 & 0.08 & 0.04 & 0.10 & 0.04 & 0.11 & 0.02 & 0.07 & 0.04 & 0.09 & 0.04 & 0.11 & 0.02 \\
\hline
\end{tabular}

Table 4. BP neural network imagery geometrical model accuracy of dataset 3

\begin{tabular}{|c|c|c|c|c|c|c|c|c|c|c|c|c|}
\hline \multirow{3}{*}{$\begin{array}{l}\text { Number } \\
\text { of node }\end{array}$} & \multicolumn{6}{|c|}{ Control point (pixel) } & \multicolumn{6}{|c|}{ Check point(pixel) } \\
\hline & \multicolumn{2}{|c|}{$\mathrm{X}$} & \multicolumn{2}{|c|}{$\mathrm{Y}$} & \multicolumn{2}{|c|}{ Planarity } & \multicolumn{2}{|c|}{$\mathrm{X}$} & \multicolumn{2}{|c|}{$\mathrm{Y}$} & \multicolumn{2}{|c|}{ Planarity } \\
\hline & Max & RMS & Max & RMS & Max & RMS & Max & RMS & Max & RMS & Max & RMS \\
\hline 2 & 79.56 & 42.58 & 49.25 & 20.08 & 380.91 & 43.87 & 68.59 & 23.61 & 54.25 & 17.67 & 87.45 & 25.87 \\
\hline 3 & 67.91 & 43.68 & 50.61 & 19.90 & 399.47 & 45.09 & 5.50 & 12.62 & 20.28 & 6.92 & 31.31 & 8.80 \\
\hline 4 & 81.49 & 42.78 & 47.86 & 19.73 & 387.45 & 44.44 & 50.15 & 19.75 & 39.67 & 16.30 & 63.95 & 20.61 \\
\hline 5 & 99.73 & 38.06 & 73.31 & 15.62 & 281.96 & 34.48 & 19.69 & 21.22 & 12.85 & 6.39 & 55.18 & 14.81 \\
\hline 6 & 78.55 & 29.09 & 60.23 & 7.15 & 299.51 & 28.93 & 90.16 & 40.69 & 105.67 & 40.68 & 107.34 & 29.46 \\
\hline 7 & 52.23 & 13.35 & 51.54 & 6.65 & 79.12 & 12.47 & 9.41 & 5.88 & 3.39 & 2.93 & 10.49 & 3.06 \\
\hline 8 & 60.89 & 45.18 & 32.19 & 16.50 & 413.02 & 43.76 & 73.10 & 44.19 & 38.32 & 13.79 & 117.12 & 39.98 \\
\hline
\end{tabular}

Table 5. Terrain-dependent BP neural network imagery geometrical model accuracy of dataset 1

\begin{tabular}{|c|c|c|c|c|c|c|c|c|c|c|c|c|}
\hline \multirow[t]{3}{*}{ Test } & \multicolumn{6}{|c|}{ Control point (pixel) } & \multicolumn{6}{|c|}{ Check point(pixel) } \\
\hline & \multicolumn{2}{|c|}{$\mathrm{X}$} & \multicolumn{2}{|c|}{$\mathrm{Y}$} & \multicolumn{2}{|c|}{ Planarity } & \multicolumn{2}{|c|}{$\mathrm{X}$} & \multicolumn{2}{|c|}{$\mathrm{Y}$} & \multicolumn{2}{|c|}{ Planarity } \\
\hline & Max & RMS & Max & RMS & Max & RMS & Max & RMS & Max & RMS & Max & RMS \\
\hline $\begin{array}{c}\text { Dataset } 1 \\
\text { terrain- } \\
\text { independent }\end{array}$ & 0.07 & 0.03 & 0.09 & 0.04 & 1.16 & 0.05 & 0.07 & 0.03 & 0.08 & 0.03 & 0.24 & 0.04 \\
\hline $\begin{array}{c}\text { Dataset } 2 \\
\text { terrain- } \\
\text { independent }\end{array}$ & 0.07 & 0.03 & 0.11 & 0.05 & 1.51 & 0.05 & 0.06 & 0.03 & 0.11 & 0.05 & 0.40 & 0.06 \\
\hline $\begin{array}{c}\text { Dataset } 3 \\
\text { terrain- } \\
\text { independent }\end{array}$ & 0.06 & 0.03 & 0.13 & 0.05 & 1.54 & 0.06 & 0.06 & 0.03 & 0.10 & 0.03 & 0.37 & 0.05 \\
\hline $\begin{array}{c}\text { Dataset } 1 \\
\text { terrain-dependent }\end{array}$ & 101.95 & 12.57 & 33.11 & 5.22 & 20749.01 & 13.61 & 11.44 & 4.35 & 3.85 & 3.87 & 339.06 & 5.82 \\
\hline
\end{tabular}

Table 6. RFM accuracy of all the datasets 
From Tables 2,3,4, for the terrain-independent experiments, the planarity accuracy of the BP neural network imagery geometrical model is increasing with the hidden node number growing, as is shown in Figure 3. When the node number of hidden layer is more than 4, the max BP neural network imagery geometrical model error is 0.04 pixel, is the highest accuracy in the RFM test in Table 6, which can resemble the physical sensor model very well. And when the node number is 4 , the accuracy is higher than 0.2 pixel, which is usually a indicator for satellite imagery geometry process. The accuracy is stable, when the node number is more than 5 , and equals to 0.02 pixel. While in the RFM test, all the dataset Max error are bigger than 0.2pixels, and the highest accuracy is 0.04 pixel.

For the terrain-dependent experiments, from Table 5, the max BP neural network imagery geometrical model error is 117.12 pixel, and the max RMS is 39.98 pixel. While, the max BP neural network imagery geometrical model error in the terraindependent experiment is 9.95 pixel, and the max RMS is 2.05 pixel. The fitting accuracy of the terrain-independent method is much higher than the terrain-independent one, which is very alike the RFM (Tao, C. V., Hu, Y., 2001). In this paper, the RFM terrain-dependent and terrain-independent test, the max error is 339.06 pixel, 0.40pixel, and the max RMS is 5.82 pixel, 0.06 pixel. The number and distribution of GCPs are the main reason of the difference. As the control points of the terrainindependent experiments are almost 5 times more than the terrain-dependent one, with higher positioning accuracy.

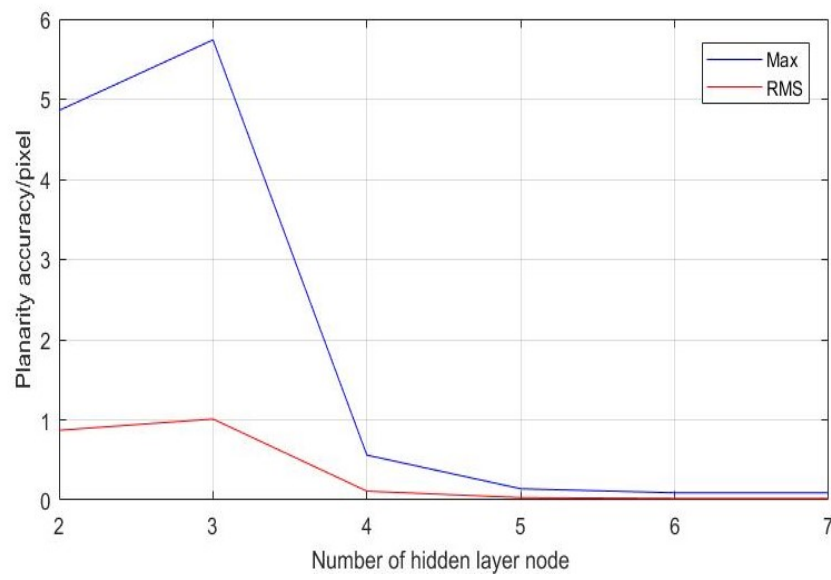

(a)Dataset 1

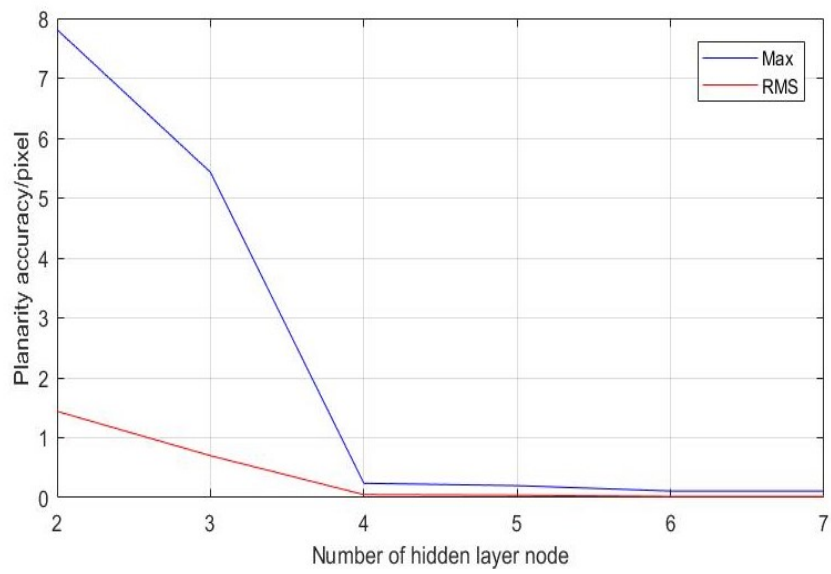

(b)Dataset 2

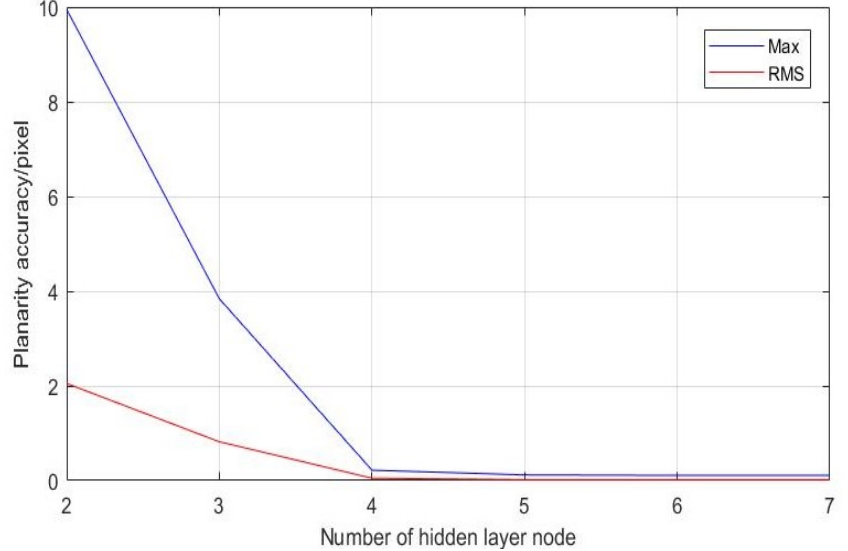

(c)Dataset 3

Figure 3. The terrain-indepedent BP neural network imagery geometrical model accuracy with different hidden layer node

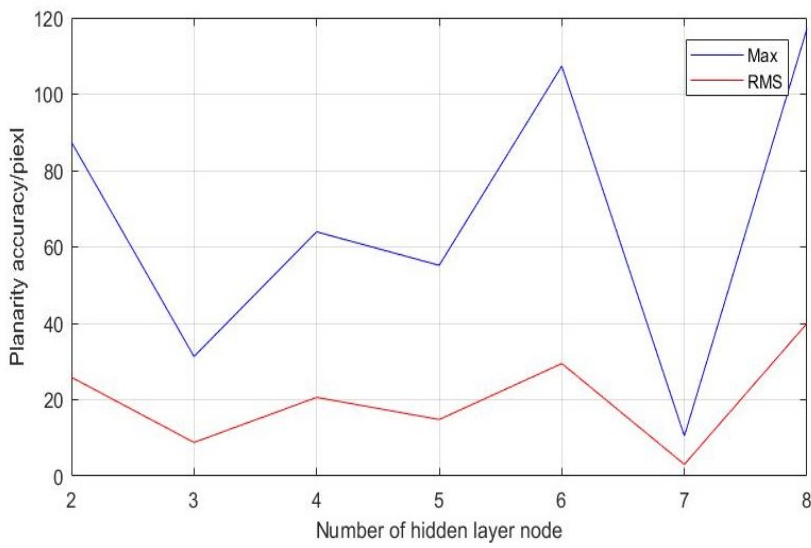

Figure 4. The terrain-depedent BP neural network imagery geometrical model accuracy of dataset 1 with different hidden layer node

The node number of hidden layer in BP neural network imagery geometrical model training does not effect the RMS prominently in the terrain-independent experiments, after it grows to 4 . When the node number from 5 to 7 , the RMS is between 0.02 and 0.04 pixel, and the max error is between 0.09 pixel to 0.2 pixel. However, both max error and RMS are smallest from the node number in hidden layer is 6 , in the three datasets, which can be easily seen from Figure 2. Thus, we can choose 6 nodes in the hidden layer to save the calculation and time costs in the terrain-independent training process.

In the terrain-dependent experiment, no matter the Max error or RMS are changing greatly, from 10.49 pixel to 117.12 pixel and 3.06 pixel to 39.98 pixel, respectively. It needs more high accuracy control points to train a better net. And when the node number is 6 , the RMS and Max error are smallest, which is very similar with the terrain-independent experiments, acoording to Figure 3. For both the terrain-independent and the terraindependent method, 7 nodes in the hidden layer may be a good choice. 


\section{CONCLUSION}

The generalized sensor models is always of great interest in the photogrammetry and remote sensing community for the raising new kinds of sensors and imaging systems. The BP neural network imagery geometrical model is proposed as a test of new generalized sensor model in this paper, which is capable to achieve a high approximation accuracy of the physical sensor mode. The same method of RFM is used to generate the training data for the experiment datasets, and the accuracy of different number of hidden layer node is tested. Meanwhile, we also put forward both the terrain-dependent and terrain-independent experiments to test the accuracy difference for training datasets. The results of the terrain-independent experiments show that, the approximation accuracy of BP neural network imagery geometrical model with one hidden layer is extremely high for satellite imagery photogrammetric restitution, which is with the same training data and of the same accuracy as RFM.

Next, we will test the structure of the BP neural network, such as hidden layer numbers and other neural network models, to raise the approximation accuracy.

\section{REFERENCES}

Fraser, C.S., Baltsavias, E., Gruen, A., 2002. Processing of Ikonos imagery for submetre 3D geopositioning and building extraction. ISPRS J. Photogram. Remote Sens., 56(3), 177-194.

Fraser, C.S., Yamakawa, T., 2004. Insights into the affine model for satellite sensor orientation. ISPRS J. Photogram. Remote Sens. , 58 (5-6), 275-288.

Gugan, D.J., Dowman, I.J., 1988. Topographic mapping from spot imagery. Photogram. Eng. Remote Sens. 54(10), 14091414.

Grodecki, J., Dial, G., 2003. Block adjustment of highresolution satellite images described by rational polynomials. Photogram. Eng. Remote Sens, 69 (1), 59-68.

Hu C., 2010. Improved BP neural network algorithm for GPS height conversion. In: Proceedings of 2010 International Conference on Communications and Intelligence Information Security. Nanning, Guangxi, China, 13-14 October.

Kim, T., Dowman, I., 2006. Comparison of two physical sensor models for satellite images: position-rotation model and orbitattitude model. Photogram. Rec. 21(114), 110-123.

Jeong, J, Kim, T., 2015. Comparison of positioning accuracy of a rigorous sensor model and two rational function models for weak stereo geometry. ISPRS Journal of Photogrammetry and Remote Sensing, 108, 172-182.

Radhadevi, P.V., Ramachandran, R., MuraliMohan, A.S.R.K.V., 1998. Restitution of IRS-1C PAN data using an orbit attitude model and minimum control. ISPRS J. Photogram. Remote Sen, 53(5), 262-271.

Tao, C. V., Hu, Y., 2001. A comprehensive study of the rational function model for photogrammetric processing. Photogrammetric engineering \& remote sensing, 67(12), 13471357.
Tao, C., Hu, Y., Jiang, W., 2004. Photogrammetric exploitation of IKONOS imagery for mapping applications. Int. J. Remote Sens.25(14), 2833-2853.

Wang C., Wu F., Shi Z., Zhang D., 2016. Indoor positioning technique by combining RFID and particleswarm optimizationbased back propagation neural network. Optik, 127, 6839-6849.

Xiao Z., Ye S.J., Zhong B., Sun C.X., 2009. BP neural network with rough set for short term load forecasing, Expert Syst. Appl., 36 (1), 273-279.

Yavari S., Zoej M. J. V., Mohammadzadeh A., and Mokhtarzade M., 2013. Particle swarm optimization of RFM for georeferencing of satellite images. IEEE GEOSCIENCE AND REMOTE SENSING LETTERS, 10(1), 135-139.

Yue C. Y., Zheng Y. C., Tao Y. L., 2013. Study on Space-borne Laser Altimeter Supported Satellite Photogrammetry. Spacecraft Recovery \& Remote Sensing, 34(4), 71-76.

Zhang, G., Yuan, X., 2006. On RPC model of satellite imagery. Geo-spatial Information Science, 9(4), 285-292.

Zhang H., Shi X., Cao L., Deng G., 2012. A new indoor location technology using back propagation neural network and improved centroid algorithm. In: Proceedings of 31st Chinese Control Conference, Hefei, China, 25-27 July.

Zhao R., Jiang Y., Zhang G., Deng M., Yang F., 2017. GEOMETRIC ACCURACY EVALUATION OF YG-18 SATELLITE IMAGERY BASED ON RFM , The Photogrammetric Record, 32(157): 33-47. 